\title{
Development and Validation of a Virtual Reality-Based Training Program for Promoting Subjective Well-Being
}

\author{
Junhyung Kim¹, Young Hoon Jung², Yu-Bin Shin², Min-Kyeong Kim², \\ Hyojung Eom², Eunjoo Kim²,3, Joohan Kim4, and Jae-Jin Kim ${ }^{2,3 凶}$ \\ ${ }^{1}$ Department of Psychiatry, Korea University Guro Hospital, Korea University College of Medicine, Seoul, Republic of Korea \\ ${ }^{2}$ Institute of Behavioral Science in Medicine, Yonsei University College of Medicine, Seoul, Republic of Korea \\ ${ }^{3}$ Department of Psychiatry, Yonsei University College of Medicine, Seoul, Republic of Korea \\ ${ }^{4}$ Department of Communication, Yonsei University, Seoul, Republic of Korea
}

Objective Enhancing subjective well-being is an effective way to improve mental health. This study aimed to validate a virtual realitybased interactive feedback program as an intervention tool for promoting subjective well-being.

Methods Thirty-six males participated in this program, consisting of three tasks constructed based on the theories of positive psychology: 'Experience-based problem recognition task', 'Future self-based success story expression task', and 'Strength expression task'. Participants rated visual analog scores associated with each of the tasks' contents. The concurrent validity of task scores was evaluated by correlations with the psychological scale scores.

Results The total task score was positively correlated with scores of Mental Health Continuum-Short Form (MHC-SF) emotional wellbeing and psychological well-being, Rosenberg's Self-Esteem Scale, Dispositional Hope Scale agency dimension and pathways dimension, and Life Orientation Test Revised, but not with MHC-SF social well-being scores. After controlling for the effects of the other task scores, the task scores had linear relationships with certain psychological assessments.

Conclusion Since the task scores are closely related to indicators of well-being, self-esteem, hope, and optimism, the program contents are well associated with certain aspects of subjective well-being and thus may be available for training that improves subjective well-being through interactive feedback.

Psychiatry Investig 2020;17(12):1207-1215

Key Words Virtual reality-based training, Subjective well-being, Self-esteem, Hope, Optimism.

\section{INTRODUCTION}

Mental health is defined as "... a state of well-being in which the individual realizes his or her own abilities, can cope with the normal state of life, can work productively and fruitfully, and is able to make a contribution to his or her community" by the World Health Organization, ${ }^{1}$ suggesting that mental health is the existence of well-being. Although well-being is a complicated concept, ${ }^{2}$ two conceptual approaches are suggested: eudaimonic and hedonic. An eudaimonic approach sug-

Received: August 19, 2020 Revised: September 27, 2020

Accepted: October 5, 2020

$\triangle$ Correspondence: Jae-Jin Kim, MD, PhD

Department of Psychiatry, Yonsei University Gangnam Severance Hospital, 211 Eonju-ro, Gangnam-gu, Seoul 06273, Republic of Korea

Tel: +82-2-2019-3341, Fax: +82-2-2019-4926, E-mail: jaejkim@yonsei.ac.kr

(c) This is an Open Access article distributed under the terms of the Creative Commons Attribution Non-Commercial License (https://creativecommons.org/licenses/by$\mathrm{nc} / 4.0$ ) which permits unrestricted non-commercial use, distribution, and reproduction in any medium, provided the original work is properly cited. gests one's true inner self as the concept of psychological wellbeing, which is defined by the degree of which a person is fully functioning and focusing on personal growth, ${ }^{2,3}$ whereas a hedonic approach focuses on pleasure attainment and pain avoidance and is best encapsulated by subjective well-being. ${ }^{2}$ As several studies have employed subjective well-being as a major outcome variable of mental health, ${ }^{4-6}$ enhancing subjective well-being is an effective way to improve mental health.

To enhance well-being, positive psychology suggests focusing on positive emotions, character traits, and enabling institutions. ${ }^{7}$ This perspective emphasizes paying attention to strengths, improving the positives, and creating meaningful normal life as much as attending to weaknesses, addressing the negatives, and treating pathology. ${ }^{8}$ Positive psychotherapy systematically amplifies positive individual resources such as character strengths, meaning, and intrinsically motivated accomplishments, ${ }^{9}$ and is effective in treating psychiatric disorders and improving subjective well-being. ${ }^{10,11}$ For example, 
multiple sessions on topics associated with strengths can make people optimistic by identifying and devising their strength profiles, ${ }^{12}$ and subjective well-being can be enhanced through visualizing best possible selves, exploring wishes, and processing positive life experiences. ${ }^{13,14}$ Key factors in enhancing subjective well-being include genetically determined factors, environmental factors, and intentional cognitive, motivational, and behavioral activities. ${ }^{15}$ The last factor is proposed to be the most susceptible to change due to its focus on individual psychological processes. In the process of enhancing subjective well-being, it is posited that many psychological factors including self-esteem, hope, and optimism act interactively with subjective well-being. ${ }^{16-19}$

A training program to improve mental health should deliver interventions with demonstrated efficacy, accessibility, and sustainability. ${ }^{20}$ However, individual or group interventions offered at schools or work places are not always accessible (e.g., rural communities or small businesses) or sustainable (e.g., cost concerns). To overcome such limitations of conventional interventions, we can use technology of human-computer interaction, which is useful to improve the quality of our personal experience and promote positive functioning. ${ }^{21}$ To this date, several studies have reported positive psychology-based online interventions with promising results. ${ }^{20,22,23}$ Virtual reality (VR) can also be useful with this technology in that it immerses users in a virtual environment that reflects the needs of daily life. ${ }^{24-27}$ VR has a great potential to measure whether interventions can be transferred to everyday life, ${ }^{28}$ and can provide scientists the ability to monitor an individual's real-time behaviors when interacting with virtual agents. ${ }^{29}$ Furthermore, the use of VR reduces human resources and costs, and thus has an advantage in sustainability. ${ }^{30}$ Actually, there have been a few reports that positive psychology-based VR interventions can be useful in areas, such as inducing positive emotions in cancer patients ${ }^{31}$ and modifying dysfunctional communication in the general public. ${ }^{32}$ Taken together, VR may also have a potential to be effectively utilized as positive intervention for improving subjective well-being.

Considering both the importance of improving subjective well-being in mental health and the usefulness of VR as an intervention tool, the development of an appropriate VRbased program for cultivating well-being should be emphasized. The purpose of this study was to address the validation of a VR-based interactive feedback program for promoting subjective well-being. It was hypothesized that the behavior data collected in this program would demonstrate significant relationships with psychological assessments for subjective well-being and predict certain psychological characteristics.

\section{METHODS}

\section{Participants}

Participants were 36 male volunteers in their 20s (age range, 20-27 years; mean age, 23.7 \pm 1.9 ; mean education years, $14.9 \pm$ 1.9), recruited through advertisements in their communities. They were interviewed by a psychiatrist using the Mini-International Neuropsychiatric Interview ${ }^{33}$ to screen the current use of psychotropic medications and any history of substance use disorders, neurological disorders, and major psychiatric disorders. This study was approved by the local Institutional Review Board (IRB No. 3-2016-0107), and participants provided informed consent upon explanation of the purpose and process of the study.

\section{VR-based training}

All participants experienced the VR-based training program, "Enhancing Subjective Well-being" (Figure 1), once with the help of the built-in voice guidance. The program was run on the system including the Oculus Rift head-mounted display and touch controller (Oculus VR, LLC, USA), and consisted of three VR tasks with spoken avatars: 'Experiencebased problem recognition task,' 'Future self-based success story expression task', and 'Strength expression task.' In all tasks, participants were advised to consider and talk in detail their experiences, wishes, and thoughts. Participants' states of mind during the program were monitored with task scores for questions rated on a visual analog scale (VAS) of horizontal line with the left ('not at all': 0 point) and right ('very much': 100 point) ends. Participants performed the tasks for about 40 minutes while sitting in a chair in a quiet room. An assistant provided only help with the operation of VR equipment.

\section{Experience-based problem recognition task}

The goal of this task was to strengthen subjective well-being by exploring problems that participants experienced. The virtual instrument began with each participant standing in the 'future experience room' with a table with four books, each titled 'Family relationships,' 'Interpersonal relationships', 'Academics and Career', and 'Leisure/Habits/Health.' The participant was given voice guidance that overviewing his/her problems could be helpful in overcoming the problems. The guidance asked the participant to choose one of the books based on his/ her current life experiences. An avatar introduced as an expert then entered the room and asked the participant to express his/her difficulties and efforts on resolving the difficulties. The participant was monitored using three questions, "How great is your difficulty in the selected domain?", "How likely are these problems to be resolved?", and "How much effort have you made to resolve the problem." The VAS scores 


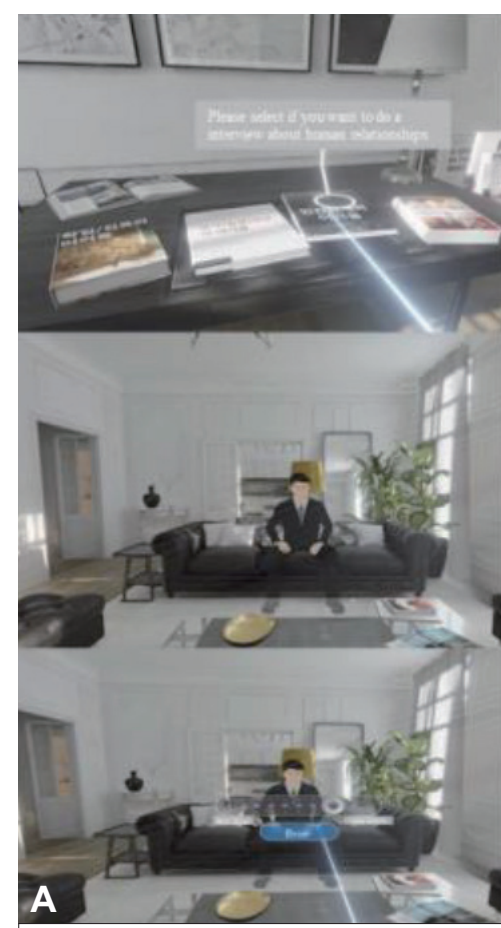

Experience-based problem recognition task

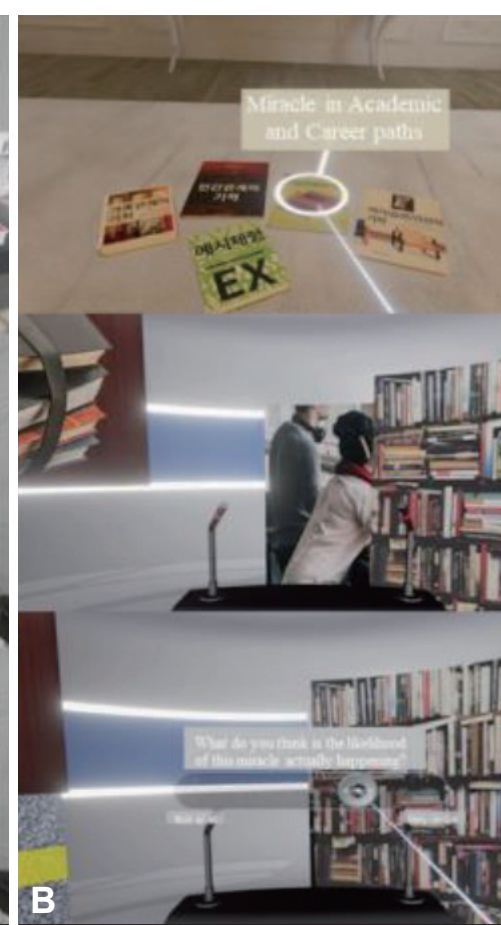

Fature self-based success story expression task

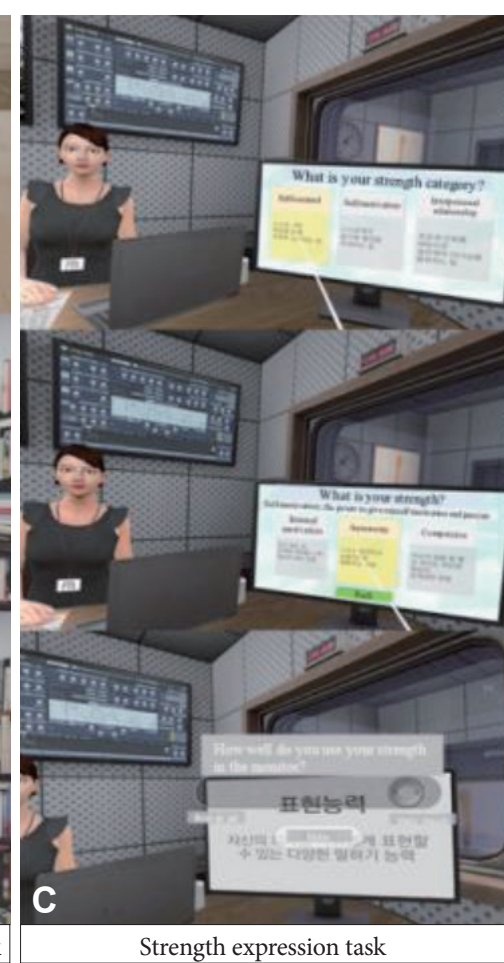

Strength expression task

Figure 1. Screenshots of the training program, "Enhancing Subjective Well-being." In the program including three tasks (A, B, and C), participants select one of several choices presented via the user interface and rate the visual analog scale constructed in the virtual environment. The program was conducted in Korean, but the examples of the help balloon in this figure are presented in English to aid understanding of readers.

were recorded and referred to as the anti-difficulty score, resolvability score, and actual effort score, respectively. The first one was calculated by subtracting the raw score from 100 to make the direction of positivity the same as the other scores.

\section{Future self-based success story expression task}

This task was developed to improve subjective well-being by visualizing a positive outlook on one's future. Each participant was virtually positioned in a room that was warm and comfortable. There were five books titled 'Example experience, 'Family relationships,' 'Interpersonal relationships', 'Academics and Career', and 'Leisure/Habits/Health', all of which represented domains of wishes. Voice guidance explained that the participant would be asked to think and talk about wishes in the selected domain in the 'miracle room.' To encourage involvement and prevent confusion, the participant visited the 'example experience room', in which an avatar introduced as a winner of 'Idol of Korea' presented an example of tasks performed in the miracle room. When the participant chose a book, he/she entered the miracle room that contained a platform and microphone and was surrounded by images associated with the domain selected. The participant was introduced as his/her desired future self, and told in public what he/she had done in specific aspects such as efforts, goals, motivations, and paths of achievement to become his/her desired future self. Then, the participant rated the VAS score for a question: "How likely is this miracle to be realized in real life?" This was referred to as the likelihood-of-realization score.

\section{Strength expression task}

The goal of this task was to increase subjective well-being by exploring personal strengths. We anticipated participants to be able to improve subjective well-being by articulating experiences in which they demonstrated their strengths. The scene began with each participant sitting in a radio studio. Voice guidance led the participant to an interview about his/ her strengths as a Proud Citizenship awardee. There was a monitor in the virtual studio, which presented three categories and three elements for each category (Self-control: emotional control, preservation, and positive emotion; Self-motivation: internal motivation, autonomy, and competence; and Interpersonal relationships: Empathy, relatedness, and expressive capacity). Explanations were provided when a pointer was placed on the box describing each strength. An avatar host asked the participant to select one element from each of the three categories. In response to the questions, the participant verbalized his/her experience with each of the selected strengths and recommended activities for developing the strengths. The strength utilization score was measured by the question: "To what extent are you taking advantage of these 
strengths?"

\section{Psychological assessments}

Participants completed the following five self-report measures after performing the tasks. The first was the Korean version of the Mental Health Continuum-Short Form (MHC-SF), which measures positive mental health using 14 items (three for emotional well-being, five for social well-being, and six for psychological well-being) and a six-point Likert scale and has Cronbach's alpha of $0.91 .^{34}$ The second was the Korean version of the Rosenberg's Self-Esteem Scale (RSES), comprised of 10 questions with a four-point Likert scale measuring selfesteem and Cronbach's alpha of $0.90 .{ }^{35}$ The third was the Ko-

Table 1. Scores rated during the virtual reality tasks and psychological scale scores

\begin{tabular}{lrc}
\hline \multicolumn{1}{c}{ Variable (range) } & Mean & $\begin{array}{c}\text { Standard } \\
\text { deviation }\end{array}$ \\
\hline Rating scores on the task & & \\
Total task score (0-500) & 296.01 & 67.08 \\
Anti-difficulty score (0-100) & 48.02 & 23.19 \\
Resolvability score (0-100) & 64.53 & 19.81 \\
Actual effort score (0-100) & 51.55 & 22.20 \\
Likelihood-of-realization score (0-100) & 62.39 & 22.74 \\
Strength utilization score (0-100) & 69.53 & 19.70 \\
Mental Health Continuum-Short Form & & \\
Emotional well-being (0-15) & 9.22 & 3.09 \\
Social well-being (0-25) & 11.31 & 4.52 \\
Psychological well-being (0-30) & 16.61 & 7.20 \\
Rosenberg's Self-Esteem Scale (10-40) & 30.69 & 6.84 \\
Dispositional Hope Scale & & \\
Agency dimension (4-16) & 11.19 & 2.55 \\
Pathways dimension (4-16) & 12.92 & 2.21 \\
Life Orientation Test Revised (10-50) & 20.72 & 4.62 \\
Simulator Sickness Questionnaire (16-80) & 24.42 & 9.78 \\
\hline
\end{tabular}

rean version of the Dispositional Hope Scale (DHS), in which four items for the agency dimension (the individual's orientation towards their goals), four for the pathways dimension (the individual's perceived ability to identify workable routes to goal attainment), and four for distractors are used with a four-point Likert scale and Cronbach's alpha of $0.77 .^{36}$ The fourth was the Korean version of Life Orientation Test Revised (LOT-R), which measures dispositional optimism using 10 items and a five-point Likert scale and has Cronbach's alpha of $0.77 .^{37,38}$ The last was the Simulator Sickness Questionnaire (SSQ), ${ }^{39} 16$-item questionnaire to examine the occurrence and severity of cybersickness when immersed in a virtual environment.

\section{Statistical analysis}

All task scores were summed for integration and the summed score was referred to as the total task score. The concurrent validity of task scores was evaluated by calculating Pearson correlations with psychological scale scores. For exploring which task scores predicted specific psychological assessments, stepwise multiple linear regression analysis was used. Each psychological scale score was used as a dependent variable, and the task score that showed significant correlation with each psychological scale score was used as an independent variable. Statistical significance was accepted at alpha level of 0.05 . All data were analyzed using Statistical Package for Social Science 25.0 (SPSS Version 25.0; IBM Corporation, Armonk, NY, USA).

\section{RESULTS}

\section{Relationships between the task scores and psychological scale scores}

Descriptive statistics of all scores obtained in the study are shown in Table 1, and correlations between the task scores and psychological scale scores are presented in Table 2. The total

Table 2. Correlations between the task scores and psychological assessment scores

\begin{tabular}{|c|c|c|c|c|c|c|}
\hline Measures & $\begin{array}{c}\text { Total task } \\
\text { score }\end{array}$ & $\begin{array}{l}\text { Anti-difficulty } \\
\text { score }\end{array}$ & $\begin{array}{l}\text { Resolvability } \\
\text { score }\end{array}$ & $\begin{array}{c}\text { Actual effort } \\
\text { score }\end{array}$ & $\begin{array}{l}\text { Likelihood-of- } \\
\text { realization score }\end{array}$ & $\begin{array}{c}\text { Strength } \\
\text { utilization score }\end{array}$ \\
\hline \multicolumn{7}{|l|}{ MHC-SF } \\
\hline Emotional well-being & $0.492^{\dagger}$ & $0.396^{*}$ & $0.373^{*}$ & 0.197 & $0.385^{*}$ & 0.308 \\
\hline Social well-being & 0.272 & -0.079 & 0.205 & $0.426^{\dagger}$ & 0.276 & 0.095 \\
\hline Psychological well-being & $0.501^{\dagger}$ & 0.141 & 0.284 & $0.450^{\dagger}$ & $0.391^{*}$ & $0.355^{*}$ \\
\hline RSES & $0.435^{\dagger}$ & 0.311 & $0.366^{*}$ & 0.081 & $0.347^{*}$ & 0.303 \\
\hline \multicolumn{7}{|l|}{ DHS } \\
\hline Agency dimension & $0.601^{\dagger}$ & $0.329^{*}$ & $0.375^{*}$ & $0.354^{*}$ & $0.414^{*}$ & $0.486^{\dagger}$ \\
\hline Pathways dimension & $0.451^{\dagger}$ & 0.311 & $0.452^{\dagger}$ & 0.151 & 0.280 & $0.361^{*}$ \\
\hline LOT-R & $0.378^{*}$ & 0.021 & 0.245 & -0.060 & $0.457^{\dagger}$ & 0.254 \\
\hline
\end{tabular}

${ }^{*} \mathrm{p}<0.05,{ }^{\dagger} \mathrm{p}<0.01$. RSES: Rosenberg's Self-Esteem Scale, DHS: Dispositional Hope Scale, MHC-SF: Mental Health Continuum-Short Form, LOT-R: Life Orientation Test Revised 
task score showed significant positive correlations with the scores of MHC-SF emotional well-being ( $r=0.492, \mathrm{p}<0.01$ ), MHC-SF psychological well-being $(r=0.501, p<0.01)$, RSES $(\mathrm{r}=0.435, \mathrm{p}<0.01)$, DHS agency dimension $(\mathrm{r}=0.601, \mathrm{p}<0.01)$, DHS pathways dimension $(\mathrm{r}=0.451, \mathrm{p}<0.01)$, and LOT-R $(\mathrm{r}=$ $0.378, \mathrm{p}<0.05)$, but not with the MHC-SF social well-being scores. The scatter plots of the total task score and psychological assessments are depicted in Figure 2.

In the three task scores of the experience-based problem recognition task, significant positive correlations were found in the anti-difficulty score with the scores of MHC-SF emotional well-being $(\mathrm{r}=0.396, \mathrm{p}<0.05)$ and DHS agency dimension $(r=0.329, p<0.05)$, the resolvability score with the scores of MHC-SF emotional well-being $(r=0.373, p<0.05)$, RSES $(r=$ $0.366, \mathrm{p}<0.05)$, DHS agency dimension $(\mathrm{r}=0.375, \mathrm{p}<0.05)$, and DHS pathways dimension $(r=0.452, p<0.01)$, the actual effort score with the scores of MHC-SF social well-being ( $r=0.426$, $\mathrm{p}<0.01)$, MHC-SF psychological well-being $(\mathrm{r}=0.450, \mathrm{p}<0.01)$, and DHS agency dimension $(\mathrm{r}=0.354, \mathrm{p}<0.05)$. The likelihoodof-realization score in the future self-based success story expression task was positively correlated with the scores of MHC-SF emotional well-being $(r=0.385, p<0.05)$, MHC-SF psychological well-being $(\mathrm{r}=0.391, \mathrm{p}<0.05)$, RSES $(\mathrm{r}=0.347, \mathrm{p}<$ $0.05)$, DHS agency dimension $(\mathrm{r}=0.414, \mathrm{p}<0.05)$, and LOT- $\mathrm{R}$ $(\mathrm{r}=0.457, \mathrm{p}<0.01)$. The strength utilization score in the strength expression task also showed positive correlations with the scores of MHC-SF psychological well-being ( $r=0.355, \mathrm{p}<0.05)$, DHS agency dimension $(\mathrm{r}=0.486, \mathrm{p}<0.01)$, and DHS pathways dimension $(r=0.361, \mathrm{p}<0.05)$.

\section{Results from step-wise multiple linear regression analyses}

After controlling the effects of the other task scores, the task scores showing linear relationships with certain psychological assessments are presented in Table 3. The anti-difficulty score predicted only the MHC-SF emotional well-being score ( $\mathrm{p}=$ $0.019)$. The resolvability score predicted the RSES $(p=0.028)$ and DHS agency and pathways dimension scores $(\mathrm{p}=0.041$ and $\mathrm{p}=0.006$, respectively). The actual effort score predicted the MHC-SF social and psychological well-being scores $(\mathrm{p}=$ 0.01 and $p=0.015$, respectively). The likelihood-of-realization score predicted the MHC-SF emotional and psychological well-being scores $(\mathrm{p}=0.023$ and $\mathrm{p}=0.047$, respectively) and LOT-R score $(\mathrm{p}=0.005)$. The strength utilization score predicted only the DHS agency dimension score $(\mathrm{p}=0.005)$.

\section{DISCUSSION}

The current study aimed to address the validity of our VRbased program for promoting subjective well-being. For acceptability, it is important that there are only manageable adverse effects when using the system. In this study, all participants completed the program without giving up. Given that the weighted mean SSQ score of the projection type of the headmounted display used in the current study was $29.9,{ }^{40}$ our score of 24.4 suggests that the program causes an acceptable level of adverse effects of cybersickness.

The total task score calculated after completing the program showed a moderate correlation with most of the scale scores
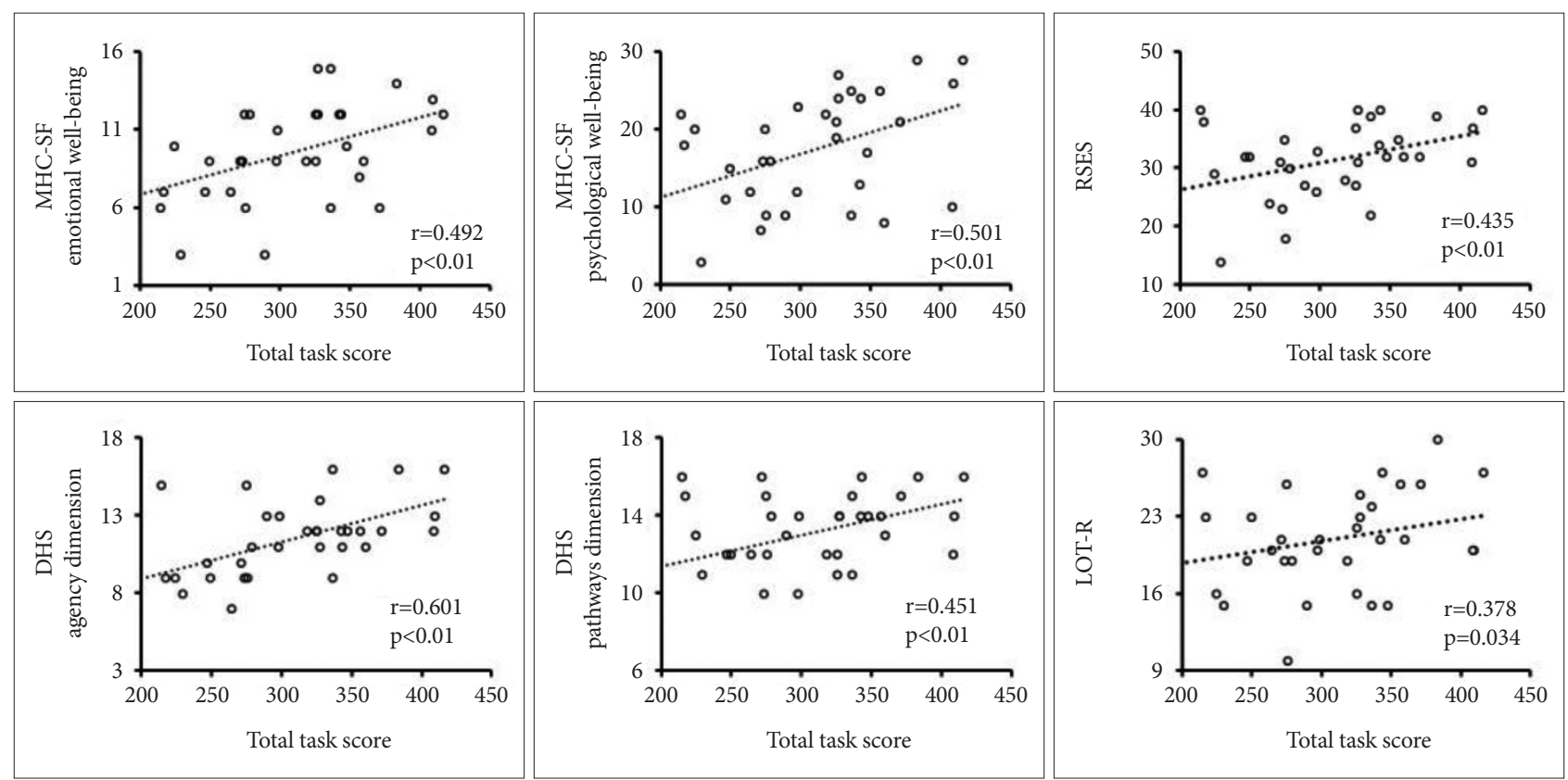

Figure 2. The plots of correlations between the total task score and psychological scale scores. MHC-SF: Mental Health Continuum-Short Form, RSES: Rosenberg Self-Esteem Scale, DHS: Dispositional Hope Scale, LOT-R: Life Orientation Test Revised. 
Table 3. Step-wise multiple linear regression model of psychological assessments by the task score

\begin{tabular}{|c|c|c|c|c|c|c|}
\hline \multirow[b]{2}{*}{ Dependent variable } & \multicolumn{2}{|c|}{ Anti-difficulty score } & \multicolumn{2}{|c|}{ Actual effort score } & \multicolumn{2}{|c|}{ Likelihood-of-realization score } \\
\hline & $\begin{array}{c}\text { Standardized } \\
\text { coefficient }(95 \% \text { CI })\end{array}$ & $\mathrm{p}$ & $\begin{array}{c}\text { Standardized } \\
\text { coefficient }(95 \% \mathrm{CI})\end{array}$ & $\mathrm{p}$ & $\begin{array}{c}\text { Standardized } \\
\text { coefficient }(95 \% \mathrm{CI})\end{array}$ & $\mathrm{p}$ \\
\hline \multicolumn{7}{|l|}{ MHC-SF } \\
\hline Emotional well-being & $0.366(0.009-0.089)$ & 0.019 & & & $0.354(0.007-0.089)$ & 0.023 \\
\hline Social well-being & & & $0.426(0.023-0.151)$ & 0.01 & & \\
\hline Psychological well-being & & & $0.384(0.026-0.223)$ & 0.015 & $0.310(0.002-0.194)$ & 0.047 \\
\hline LOT-R & & & & & $0.457(0.030-0.156)$ & 0.005 \\
\hline \multirow[b]{2}{*}{ Dependent variable } & Resolvability sco & & \multicolumn{2}{|c|}{ Strength utilization score } & & \\
\hline & $\begin{array}{c}\text { Standardized } \\
\text { coefficient }(95 \% \mathrm{CI})\end{array}$ & $\mathrm{p}$ & $\begin{array}{c}\text { Standardized } \\
\text { coefficient }(95 \% \mathrm{CI})\end{array}$ & $\mathrm{p}$ & & \\
\hline RSES & $0.366(0.014-0.238)$ & 0.028 & & & & \\
\hline \multicolumn{7}{|l|}{ DHS } \\
\hline Agency dimension & $0.308(0.002-0.077)$ & 0.041 & $0.439(0.019-0.095)$ & 0.005 & & \\
\hline Pathways dimension & $0.452(0.016-0.085)$ & 0.006 & & & & \\
\hline
\end{tabular}

CI: confidence interval, MHC-SF: Mental Health Continuum-Short Form, LOT-R: Life Orientation Test Revised, RSES: Rosenberg's Self-Esteem Scale, DHS: Dispositional Hope Scale

for psychological factors affecting subjective well-being, suggesting that the total task score may have good concurrent validity for assessing well-being, self-esteem, hope, and optimism. Unlike other measures, the MHC-SF social well-being score was not associated with the total task score, presumably because the contents of our program focused on the inner self concerning well-being. This result also reflects the fact that the elements of well-being are related to each other but are clearly distinct from each other. ${ }^{41}$

The anti-difficulty score showed a linear relationship only with the MHC-SF emotional well-being score. Since participants selected the most difficult area of their current lives, such as family relationships, interpersonal relationships, academics and career, and leisure/habits/health, during the experience-based problem recognition task, the VAS score for experienced difficulty reflected the intensity of current stress. As the anti-difficulty score was the inverse of the intensity of stress experienced by participants, larger scores mean less stressful experience. Emotional well-being is the primary reflection of pleasant emotions and happiness. ${ }^{42}$ Several studies have reported that perceived stress in various aspects of the environment had negative correlations with subjective well-being. ${ }^{43,44}$ Taken together, the result that the anti-difficulty score had a specific association with emotional well-being suggests that the current level of stress has a decisive effect on emotional well-being, including happiness.

The resolvability score had a linear relationship with both agency and pathways dimensions of the DHS. The contents of the experience-based problem recognition task focused on the will and action plan, and the resolvability score was a mea- sure of the degree to which participants expected to be able to resolve the difficulties experienced. Accordingly, the higher the score, the more likely participants think that they will be able to overcome life's challenges. The direct relationship between the score and hope is consistent with the previous findings that hope is clearly related to the expectation that positive outcomes will occur through one's own plans (pathways) and motivations (agency) ${ }^{45}$ Despite the similarity between hope and optimism, however, the resolvability score showed no linear relationship with the LOT-R score. In fact, optimism is primarily concerned with the expectation that positive outcomes will occur regardless of one's actions unlike hope ${ }^{38,46}$ Some studies comparing the effects of hope and optimism reported that while both predicted life satisfaction, a positive effect on academic performance was only related to hope, not optimism. ${ }^{47,48}$ Our results indicate the importance of hope over optimism in terms of the willingness to overcome life's challenges.

The actual effort score predicted the MHC-SF social and psychological well-being scores. This score was about efforts to overcome difficulties, and thus higher scores indicate more of the effort. Such efforts are associated with stress, and much of the stress people experience is related to social factors. ${ }^{49}$ The close relationship between the degree of actual effort and social well-being is understandable in that most topics presented in the experience-based problem recognition task belonged to the social realm. The model of social well-being has focused on the individuals' evaluations of their public and social lives. ${ }^{41,50}$ Meanwhile, since psychological well-being mainly reflects the point in life at which a person realizes his/her potential and tries to resolve his/her problems, ${ }^{3}$ the close relationship be- 
tween the degree of actual effort and psychological well-being seems to be inevitable.

The likelihood-of-realization score predicted the MHC-SF emotional and psychological well-being scores and LOT-R score. The future self-based success story expression task was to visualize a positive outlook on one's future. Because the score was about the participant's future positive appearance, higher scores may reflect more optimistic attitude toward his/her future goals. The task contents were based on the concept of "best possible self," a positive psychology intervention. ${ }^{14}$ Disclosive writing about possible selves has been found to improve emotional adjustment through learning about oneself, restructuring one's priorities, and gaining better insight into one's motives. ${ }^{51-54}$ In addition, emotional well-being and optimism can be increased through a program asking a person to visualize a life consistent with his/her ideal self. ${ }^{55}$ Therefore, the likelihood-of-realization score seems to be linked to subjective wellbeing and optimism through the concept of "best possible self."

The strength utilization score showed a linear relationship only with the DHS agency dimension score. The strength expression task aimed to help participants to explore and identify their character strengths. We expected the contents of this task would be associated with the process of strength identification that is important for strengthening subjective wellbeing. However, the resultant score showed association with agency dimension rather than pathways dimension of hope because the question did not ask how much participants identified their strengths, but asked how much they were taking advantage of the strengths. Higher scores indicate that participants evaluate their utilization of the strengths more positively. Therefore, our finding suggests that hope may be important to exploit strengths. Previous studies have reported that strength knowledge identifying and devising strengths has a positive correlation with hope, ${ }^{56,57}$ and hope mediates between strength use and strength knowledge. ${ }^{58}$

The interpretation of our results should be considered with caution. First, we limited participants to young men because the purpose was to only evaluate the usefulness of the program. A more intensive applicability study should be conducted with a more diverse sample including a broad range of age and female. Second, this experiment was only a one-time experience of our program. To be used for training purposes, a systematic repeating schedule is required. Third, the program relies only on subjective evaluation. Objective evaluation systems, including the use of biosignals, need to be added for further development.

In summary, our results provide evidence that our program may be valid as a tool for addressing subjective well-being. Cybersickness during the program was tolerable. The task scores from the experience-based problem recognition task showed a valid relationship with well-being and self-esteem, those from the future self-based success story expression task with well-being and optimism, and those from the strength expression task with agency dimension of hope. These results indicate that the program contents are associated with certain aspects of subjective well-being and thus may be available for training that improves it through interactive feedback. We believe that the use of our program will be an important starting point for the development of more efficient VR programs for improving subjective well-being.

\section{Acknowledgments}

This research was supported by the Brain Research Program through the National Research Foundation of Korea (NRF) funded by the Ministry of Science, ICT \& Future Planning (NRF-2015M3C7A1065053).

\section{Conflicts of Interest}

The authors have no potential conflicts of interest to disclose.

\section{Author Contributions}

Conceptualization: Jae-Jin Kim. Data curation: Yu-Bin Shin. Formal analysis: Junhyung Kim. Funding acquisition: Jae-Jin Kim. Investigation: Young Hoon Jung, Hyojung Eom. Methodology: Min-Kyeong Kim. Project administration: Yu-Bin Shin. Supervision: Jae-Jin Kim. Validation: Eunjoo Kim. Visualization: Joohan Kim. Writing_orininal draft: Junhyung Kim. Writing_-review \& editing: Joohan Kim, Jae-Jin Kim.

\section{ORCID iDs}

\section{Junhyung Kim}

Yu-Bin Shin

Min-Kyeong Kim

Hyojung Eom

Eunjoo Kim

Joohan Kim

Jae-Jin Kim https://orcid.org/0000-0001-7123-9535 https://orcid.org/0000-0002-7311-9438 https://orcid.org/0000-0001-6044-9422 https://orcid.org/0000-0003-4600-320X https://orcid.org/0000-0003-3061-2051 https://orcid.org/0000-0001-6558-536X https://orcid.org/0000-0002-1395-4562

\section{REFERENCES}

1. World Health Organization. The World Health Report 2001: Mental Health: New Understanding, New Hope. Geneva: World Health Organization; 2001.

2. Ryan RM, Deci EL. On happiness and human potentials: a review of research on hedonic and eudaimonic well-being. Annu Rev Psychol 2001; 52:141-166.

3. Ryff CD. Happiness is everything, or is it? Explorations on the meaning of psychological well-being. J Pers Soc Psychol 1989;57:1069-1081.

4. Becker C, Kirchmaier I, Trautmann ST. Marriage, parenthood and social network: Subjective well-being and mental health in old age. PLoS One 2019;14:e0218704.

5. Danzer AM, Danzer N. The long-run consequences of Chernobyl: Evidence on subjective well-being, mental health and welfare. J Pub Econ 2016;135:47-60.

6. Zhang X, Zhang X, Chen X. Happiness in the air: How does a dirty sky affect mental health and subjective well-being? J Environ Econ Manag 2017;85:81-94.

7. Seligman MEP, Csikszentmihalyi M. Positive psychology: an introduction. Am Psychol 2000;55:5-14.

8. Peterson C. A Primer in Positive Psychology. New York: Oxford University Press; 2006.

9. Rashid T. Positive psychotherapy: a strength-based approach. J Posit Psychol 2015;10:25-40. 
10. Niemiec RM, Tayyab R, Marcello S. Strong mindfulness: Integrating mindfulness and character strengths. J Ment Health Couns 2012;34: 240-253.

11. Pietrowsky R, Mikutta J. Effects of positive psychology interventions in depressive patients-a randomized control study. Psychology 2012;3: 1067-1073.

12. Munn G. Book review. Rapp CA, Goscha RJ. The strengths model: case management with people with psychiatric disabilities, 2nd edn. Oxford, Oxford University Press, 2006, p. 320. Br J Soc Work 2007;37:358-359.

13. Lyubomirsky S, Sousa L, Dickerhoof R. The costs and benefits of writing, talking, and thinking about life's triumphs and defeats. J Pers Soc Psychol 2006;90:692-708.

14. Sheldon KM, Lyubomirsky S. How to increase and sustain positive emotion: the effects of expressing gratitude and visualizing best possible selves. J Posit Psychol 2006;1:73-82.

15. Lyubomirsky S, King L, Diener E. The benefits of frequent positive affect: Does happiness lead to success? Psychol Bull 2005;131:803-855.

16. Bajaj B, Robins RW, Pande N. Mediating role of self-esteem on the relationship between mindfulness, anxiety, and depression. Pers Indiv Differ 2016;96:127-131.

17. Diener E, Diener M. Cross-cultural correlates of life satisfaction and selfesteem. J Pers Soc Psychol 1995;68:653-663.

18. Linardon J, Kothe EJ, Fuller-Tyszkiewicz M. Efficacy of psychotherapy for bulimia nervosa and binge-eating disorder on self-esteem improvement: meta-analysis. Eur Eat Disord Rev 2019;27:109-123.

19. Liu Y, Wang Z, Zhou C, Li T. Affect and self-esteem as mediators between trait resilience and psychological adjustment. Pers Indiv Differ 2014;66:92-97.

20. Mitchell J, Stanimirovic R, Klein B, Vella-Brodrick D. A randomised controlled trial of a self-guided internet intervention promoting well-being. Comput Hum Behav 2009;25:749-760.

21. Riva G, Banos RM, Botella C, Wiederhold BK, Gaggioli A. Positive technology: using interactive technologies to promote positive functioning. Cyberpsychol Behav Soc Netw 2012;15:69-77.

22. Baños RM, Etchemendy E, Mira A, Riva G, Gaggioli A, Botella C. Online positive interventions to promote well-being and resilience in the adolescent population: a narrative review. Front Psychiatry 2017;8:10.

23. Parks AC, Della Porta MD, Pierce RS, Zilca R, Lyubomirsky S. Pursuing happiness in everyday life: The characteristics and behaviors of online happiness seekers. Emotion 2012;12:1222-1234.

24. Corriveau Lecavalier N, Ouellet É, Boller B, Belleville S. Use of immersive virtual reality to assess episodic memory: a validation study in older adults. Neuropsychol Rehabil 2018;29:1-19.

25. Han K, Ku J, Kim K, Jang HJ, Park J, Kim JJ, et al. Virtual reality prototype for measurement of expression characteristics in emotional situations. Comput Biol Med 2009;39:173-179.

26. Ku J, Jang HJ, Kim KU, Park SH, Kim JJ, Kim CH, et al. Pilot study for assessing the behaviors of patients with schizophrenia towards a virtual avatar. Cyberpsychol Behav 2006;9:531-539.

27. Park KM, Ku J, Choi SH, Jang HJ, Park JY, Kim SI, et al. A virtual reality application in role-plays of social skills training for schizophrenia: a randomized, controlled trial. Psychiatry Res 2011;189:166-172.

28. Ouellet É, Boller B, Corriveau-Lecavalier N, Cloutier S, Belleville S. The Virtual Shop: a new immersive virtual reality environment and scenario for the assessment of everyday memory. J Neurosci Methods 2018;303: 126-135.

29. Gutiérrez-Maldonado J, Rus-Calafell M, González-Conde J. Creation of a new set of dynamic virtual reality faces for the assessment and training of facial emotion recognition ability. Virtual Reality 2014;18:61-71.

30. Brahnam S, Jain LC. Advanced Computational Intelligence Paradigms in Healthcare 6: Virtual Reality in Psychotherapy, Rehabilitation, and Assessment. Berlin, Heidelberg, Germany: Springer-Verlag; 2010.

31. Baños RM, Espinoza M, García-Palacios A, Cervera JM, Esquerdo G, Barrajón E, et al. A positive psychological intervention using virtual reality for patients with advanced cancer in a hospital setting: a pilot study to assess feasibility. Support Care Cancer 2013;21:263-270.

32. Kim J, Jung YH, Shin YB, Kim MK, Eom H, Kim E, et al. Feasibility of a virtual reality-based interactive feedback program for modifying dysfunctional communication: a preliminary study. BMC Psychol 2020;8: 50.

33. Lecrubier Y, Sheehan DV, Weiller E, Amorim P, Bonora I, Harnett Sheehan K, et al. The Mini International Neuropsychiatric Interview (MINI). A short diagnostic structured interview: reliability and validity according to the CIDI. Eur Psychiatry 1997;12:224-231.

34. Lim YJ. Psychometric characteristics of the Korean Mental Health Continuum-Short Form in an adolescent sample. J Psychoeduc Assess 2014; 32:356-364.

35. Bae HN, Choi SW, Yu JC, Lee JS, Choi KS. Reliability and validity of the Korean version of the Rosenberg Self-Esteem Scale (K-RSES) in adult. Mood Emot 2014;12:43-49.

36. Choi YH, Lee HK, Lee DG. Validation of the Korean version of Snyder's Dispositional Hope Scale. Kor J Soc Pers Psychol 2008;22:1-16.

37. Yom YM. The Effect of Learned Optimism Program for College Students [Master's Thesis]. Daegu: Keimyung University; 1999.

38. Scheier MF, Carver CS, Bridges MW. Distinguishing optimism from neuroticism (and trait anxiety, self-mastery, and self-esteem): a reevaluation of the Life Orientation Test. J Pers Soc Psychol 1994;67:10631078 .

39. Kennedy RS, Lane NE, Berbaum KS, Lilienthal MG. Simulator sickness questionnaire: An enhanced method for quantifying simulator sickness. Int J Aviat Psychol 1993;3:203-220.

40. Sharples S, Cobb S, Moody A, Wilson JR. Virtual reality induced symptoms and effects (VRISE): Comparison of head mounted display (HMD), desktop and projection display systems. Displays 2008;29:58-69.

41. Keyes CLM. The mental health continuum: from languishing to flourishing in life. J Health Soc Behav 2002;43:207-222.

42. Robitschek C, Keyes CLM. Keyes's model of mental health with personal growth initiative as a parsimonious predictor. J Couns Psychol 2009;56:321-329.

43. Atanes ACM, Andreoni S, Hirayama MS, Montero-Marin J, Barros VV, Ronzani TM, et al. Mindfulness, perceived stress, and subjective wellbeing: a correlational study in primary care health professionals. BMC Complement Altern Med 2015;15:303.

44. Denovan A, Macaskill A. Stress and subjective well-being among first year UK undergraduate students. J Happiness Stud 2017;18:505-525.

45. Rand KL, Cheavens JS. Hope Theory. In: Lopez S, Snyder CR, Editors. Oxford Handbook of Positive Psychology (2nd Ed.). New York: Oxford University Press, 2009, p.323-333.

46. Scheier MF, Carver CS, Bridges MW. Optimism, Pessimism, and Psychological Well-Being. In: Chang EC, Editor. Optimism and Pessimism: Implications for Theory, Research, and Practice. Washington, DC: American Psychological Association;2001, p.189-216.

47. Rand KL, Martin AD, Shea AM. Hope, but not optimism, predicts academic performance of law students beyond previous academic achievement. J Res Pers 2011;45:683-686.

48. Siddique HI, LaSalle-Ricci VH, Glass CR, Arnkoff DB, Díaz RJ. Worry, optimism, and expectations as predictors of anxiety and performance in the first year of law school. Cogn Ther Res 2006;30:667-676.

49. Coyle D, Edwards D, Hannigan B, Fothergill F. A systematic review of stress among mental health social workers. Int Soc Work 2005;48:201211.

50. Keyes CLM. Social well-being. Soc Psychol Q 1998;61:121-140.

51. Frattaroli J. Experimental disclosure and its moderators: A meta-analysis. Psychol Bull 2006;132:823-865.

52. Liau AK, Neihart MF, Teo CT, Lo CHM. Effects of the best possible self activity on subjective well-being and depressive symptoms. Asia-Pac Educ Res 2016;25:473-481.

53. Markus H, Nurius P. Possible selves. Am Psychol 1986;41:954-969.

54. Smyth JM. Written emotional expression: Effect sizes, outcome types, and moderating variables. J Consult Clin Psychol 1998;66:174-184. 
55. Lyubomirsky S, Dickerhoof R. Becoming happier takes both a will and a proper way: an experimental longitudinal intervention to boost wellbeing sonja. Emotion 2015;11:391-402.

56. Cantwell LS. Human Strengths: Differences that Bring Us Together. In: Lopez SJ, Editor. Positive Psychology: Exploring the Best in People: Dis- covering Human Strengths. Westport, CT: Praeger, 2008, p.37-54

57. Lopez SJ, Snyder CR. Handbook of Positive Psychology. Oxford, England: Oxford University Press; 2002.

58. Bowers KM, Lopez SJ. Capitalizing on personal strengths in college. J Coll Character 2010;11:1-11. 